\title{
Reverse Logistics Network Construction of Waste Electronic Products
}

\author{
Zheng Ning ${ }^{1, *}$, Gao Xin ${ }^{2}$ \\ ${ }^{1}$ Shanghai Normal University Tianhua College, Jiading, Shanghai, China \\ ${ }^{2}$ Inner Mongolia Mobile Communications Holding Co., Ltd., Hohhot, Inner Mongolia, China
}

\begin{abstract}
The acceleration of the updating and iteration of electronic products leads to the increasing types and quantity of waste electronic products, which poses a great threat to environmental protection and social development. The problem of reverse logistics of waste electronic products has gradually become the focus of social attention. This paper constructed the expected value model of the reverse logistics of waste electronic products based on the open loop supply chain, and made the implementation plan of the reverse logistics through the empirical analysis of the electronic and electrical appliances market in $\mathrm{H}$ city.
\end{abstract}

\section{Introduction}

With the upgrading of information technology and the increase of personalized needs of consumers, the iterative speed of electronic products is constantly accelerating, and a large number of waste electronic products are produced. Statistics from China's National Development and Reform Commission show that in theory, the number of discarded electronic products in China has exceeded 50 million every year for many years, and the scrap rate of electronic products has increased by an average of $20 \%$ every year ${ }^{[1]}$. Waste electronic products are not only a kind of resource but also a kind of pollutant. Reasonable treatment can realize value reuse. Building a reasonable reverse logistics network for waste electronic products has become one of the key ways to solve the problems of electronic products.

As for the research on the reverse logistics network of waste products, Moritz, Fleischmanna et al. (2000) compared the characteristics of the recycling logistics network with the forward logistics and the recycling and disposal logistics of waste goods as the reference, and described the specific structure of the recycling logistics network ${ }^{[2]}$. Theresa J Barker et al. (2010) put forward a differentiated reverse logistics network architecture model according to the different characteristics of the three different stages, and evaluated the differentiated model with AHP method ${ }^{[3]}$. Xu Yunliang (2017) pointed out that in order to promote the development of the reverse logistics system of waste electronic products towards industrialization, there are three options: manufacturers building a unique reverse logistics system, manufacturers jointly building a recovery and disposal enterprise, and recycling and processing enterprises engaged in reverse logistics alone ${ }^{[4]}$. Aiming at the current situation of electronic product recycling in China,
$\mathrm{Xu}$ Jian et al. (2015) constructed a network recycling model with the production enterprises as the core and the participation of all sectors of society ${ }^{[5]}$. He Yi et al. (2016) carefully explored the factors that promote the development of reverse logistics in the electronic product industry, and described two kinds of electronic product reverse logistics system network structures of open loop and closed loop, as well as five kinds of network architectures of direct recycling, repairing, regenerating, remanufacturing and formal disposing ${ }^{[6]}$.

\section{Reverse Logistics Model Construction of Waste Electronic Products}

Considering that the production enterprises of electronic products may not have the ability and willingness to recycle electronic products, this paper adopts the recycling mode under the open-loop supply chain. That means, the recycled electronic products are not returned to the original manufacturer, but shipped to other enterprises, such as third-party manufacturers or professional recycling companies for recycling treatment, and then returned to the raw material supplier for landfill, incineration and other treatment.

The expected value model proposed by Dantizig is applied to construct the reverse logistics model of electronic products as shown in Figure 1. The model consists of three parts: (1) Recycling collection point. The recycling collection point can be a specially set up recycling center, or it can be a retail store of electronic products, responsible for collecting all kinds of discarded electronic products. (2) Processing point. The processing point is responsible for disassembling, decomposing, sorting and crushing the recovered electronic products. (3) Sales point. Reselling or reusing the separated valuable materials. 


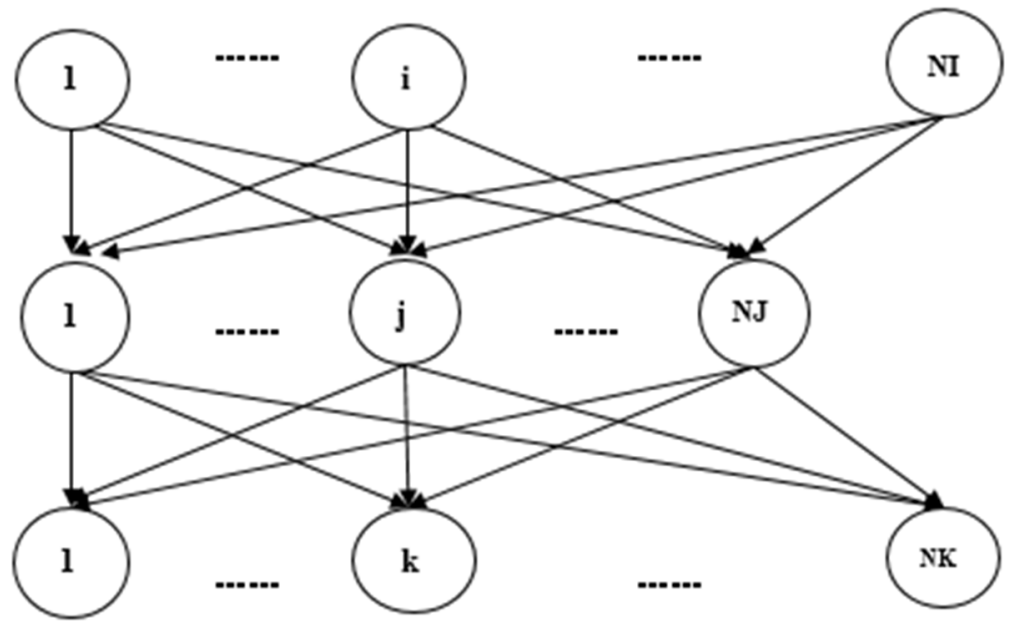

Fig. 1 Reverse logistics model of waste electronic products

According to the model, the objective function based on profit maximization is established:

$$
\begin{aligned}
\max E(\pi)= & E\left(\sum_{j} \sum_{k} \sum_{p} x^{\prime}{ }_{j k p} p r_{k p}-\sum_{i} \sum_{j} \sum_{p} x_{i j p} t_{i j p}-\sum_{j} \sum_{k} \sum_{p} x^{\prime}{ }_{i j k p} t^{\prime}{ }_{i j k p}-\sum_{i} \sum_{j} \sum_{p} x_{i j p} c^{\prime}{ }_{j p}\right. \\
& \left.-\sum_{j} c^{\prime}{ }_{i j} f_{j}-\sum_{i} c_{i}-\sum_{i} \sum_{j} \sum_{p} x^{\prime}{ }_{i j p} c_{i p}-\sum_{j} \sum_{p} u_{p} M_{k p}-\sum_{j} \sum_{p} v_{p} N_{k p}\right)
\end{aligned}
$$

S.T.

$$
\begin{aligned}
& \sum_{j} x_{i j p}=E\left(R_{i p}\right) \forall i, p \\
& \sum_{i} \sum_{j} \sum_{p} x_{i j p}=\sum_{i} \sum_{j} \sum_{p} x^{\prime}{ }_{j k p}, \forall j, p \\
& E\left(d_{k p}\right)-\sum_{j} x^{\prime}{ }_{j k p}=M_{k p}, \forall k, p \\
& \sum_{p} x^{\prime}{ }_{j k p}-E\left(d_{k p}\right)=N_{k p}, \forall k, p \\
& \sum_{i} \sum_{p} x_{i j p} \leq \max _{j} \cdot f_{j}, \forall j \\
& \sum_{i} \sum_{p} x_{i j p} \geq \min _{j} \cdot f_{j}, \forall j \\
& x_{i j p}, x^{\prime}{ }_{j k p} \geq 0 \\
& f_{i} \in\{0,1\}
\end{aligned}
$$

$\mathrm{i}$ stands for the set of product recycling points $\mathrm{i}$ $\in\{1,2, \Lambda, N I\}$;

$\mathrm{j}$ stands for the set of processing plants $\mathrm{j}$ $\in\{1,2, \Lambda, N J\}$;

$\mathrm{k}$ stands for the set of sales points $\mathrm{k}$ $\in\{1,2, \Lambda, N K\}$;

$\mathrm{p}$ stands for the set of recovered products $\mathrm{p}$ $\in\{1,2, \Lambda, N P\}$;

$u_{p}$ represents the loss of out of stock units of product $\mathrm{p}$;

$v_{p}$ represents the oversupply unit handling cost of product $\mathrm{p}$;

$M_{k p}$ represents the quantity out of stock of product $\mathrm{p}$ at sales point $\mathrm{k}$;
$N_{k p}$ represents the excess supply of product $\mathrm{p}$ at sales point $\mathrm{k}$;

$\max _{j}$ is the maximum processing capacity of processing plant $\mathrm{j}$;

$\min _{i}$ is the minimum processing capacity of processing plant $\mathrm{j}$;

$p r_{k p}$ is the selling price of product $\mathrm{p}$ at the sales point k;

$c^{\prime}{ }_{j p}$ is the unit processing cost of product $\mathrm{p}$ in processing plant $\mathrm{j}$;

$c^{\prime}{ }_{j}$ is the fixed cost of processing plant $\mathrm{j}$;

$c_{i}$ is the fixed cost of collection point $\mathrm{i}$;

$c_{i p}$ is the recovery price of product $\mathrm{p}$ recovered at the collection point $i$;

$t_{i j p}$ is the unit product freight of product $\mathrm{p}$ from $\mathrm{i}$ to $\mathrm{j}$;

$t^{\prime}{ }_{j k p}$ is the unit product freight of product $\mathrm{p}$ from $\mathrm{j}$ to $\mathrm{k}$;

$R_{i p}$ is the quantity of product $\mathrm{p}$ recovered at collection point $\mathrm{i}$;

$d_{k p}$ is the demand for product $\mathrm{p}$ at the sales point $\mathrm{k}$;

The decision variables include $x_{i j p}, x_{j k p}^{\prime}, f_{j}$, in which

$x_{i j p}$ is the quantity of product $\mathrm{p}$ from $\mathrm{i}$ to $\mathrm{j}$;

$x^{\prime}{ }_{j k p}$ is the quantity of product $\mathrm{p}$ from $\mathrm{j}$ to $\mathrm{k}$;

$$
f_{j}=\left\{\begin{array}{c}
1, \text { choosing processing plant } j \\
0, \text { or else }
\end{array}\right.
$$

Model analysis: 


$$
\begin{aligned}
& \sum_{k} \sum_{p} x^{\prime}{ }_{j k p} p r_{k p}: \text { proceeds from product sales } \\
& \sum_{i} \sum_{j} \sum_{p} x_{i j p} t_{i j p}+\sum_{j} \sum_{k} \sum_{p} x^{\prime}{ }_{i j k p} t^{\prime}{ }_{i j k p}
\end{aligned}
$$

transportation costs

$\sum_{j} \sum_{p} x_{i j p} c^{\prime}{ }_{j p}:$ processing cost

$\sum_{j} c^{\prime}{ }_{j} f_{j}:$ fixed costs of processing plants

$\sum_{i} c_{i}:$ fixed costs at the collection point

$\sum_{i} \sum_{j} \sum_{p} x^{\prime}{ }_{i j p} c_{i p}:$ the recovery cost of the recovered product

$\sum_{j} \sum_{p} u_{p} M_{k p}:$ the cost of breach of contract when out of stock

$\sum_{j} \sum_{p} v_{p} N_{k p}:$ disposal revenue from excess supply

In the constraint conditions, (2) ensures that all waste products can be recycled, (3) represents the flow balance of the processing plant, (4) represents out of stock, (5) represents excess supply, (6) and (7) represents the capacity constraint of the processing plant. (8) represents non-negative constraint, and (9) represents 0-1 constraint.

\section{An Empirical Analysis on the Reverse Logistics of Waste Electronic Products in $\mathrm{H}$ City}

$\mathrm{H}$ City is located in the central part of Inner Mongolia Autonomous Region, at the southern foot of Daqing Mountain. It is the capital of Inner Mongolia Autonomous Region, and also the political and cultural center and transportation hub of Inner Mongolia Autonomous Region.

\subsection{Market analysis of electronic products in $\mathrm{H}$ city}

(1) IT market analysis. H City has the largest computer market in Inner Mongolia and the first "Computer Street" in North China. Now "Computer Street" has become a well-known leading computer market in northern China. More than $90 \%$ of the enterprises that develop and operate computers and related technologies in $\mathrm{H}$ city are gathered in this very dynamic commercial hub.

(2) Household appliance market analysis. Home appliance chain enterprises in $\mathrm{H}$ city mainly include Gome Electrical Appliance City, Suning Electrical Appliance City, Dongge Electrical Appliance City and Five Star Electrical Appliance City. In addition, there are chain supermarkets such as Wal-Mart, Beijing Hualian, Victory, MeetAll, Carrefour and other chain supermarkets. They start with small appliances that don't need after-sales service, gradually expand to large household appliances.

(3) Communication market analysis. The communication market of $\mathrm{H}$ city is relatively developed. There are not only Apple stores, Samsung stores, Chengxin Digital Plaza, Ego Digital Plaza, Hetai Digital Plaza and other mobile phone hypermarkets, but also mobile phone stores set up by Putian, Blue Ocean and other mobile phone chain stores and home appliance stores such as Gome and Suning. In addition, there are also various types of businesses, including mobile phone areas in the shopping malls, such as Wanda Plaza, Wangfujing, Victory and ethnic shopping malls, and traditional retail stores and second-hand mobile phone trading markets.

\subsection{The Condition Analysis of Implementing Reverse Logistics in H City}

(1) Analysis of traffic conditions. H City has perfect transportation infrastructure, with the comprehensive development of roads, railways and civil aviation, forming a comprehensive transportation network and providing convenient transportation infrastructure conditions for the development of modern logistics industry. In order to adapt to the development of the national economy, $\mathrm{H}$ City has formed a multi-level comprehensive transportation network structure with railways and trunk highways as the backbone, supplemented by air transportation. It has a strong ability of convenient passenger transit and transfer, smooth distribution and circulation of goods and materials.

(2) Analysis of storage conditions. H City now has 32 storage centers of a certain scale, covering various industries, with a storage capacity of 619,000 square meters. The total amount of H's existing warehouses can basically meet the requirements of recent social and economic development, but most of the existing warehouses have single functions and low overall utilization rate. Except for a few warehouses which also have reprocessing function, most of them only have warehousing function, a considerable part of the warehouses is in the idle state, and the resources have not been fully utilized.

(3) Analysis of logistics informatization. In recent years, $\mathrm{H}$ city has accelerated the construction of data and broadband network, and the regional informatization level has been increasingly improved. Now, a pattern of coexisting development of several communication operators, such as China Netcom, China Unicom, China Railcom and China Mobile, has been formed. It has a relatively leading communication infrastructure and communication capacity in China, and the information infrastructure system has been initially established. ERP system of industrial enterprises and management information system of logistics enterprises have been applied. A small number of logistics enterprises, such as $\mathrm{H}$ City Jinzhou Freight Stowage Company, have established a logistics information system and equipped their vehicles with a GPS system.

It can be seen from the above analysis that $\mathrm{H}$ City has a relatively comprehensive logistics infrastructure, which 
provides a good operating space for the development of recycling logistics in the future.

\subsection{Parameter Setting of Reverse Logistics Model of Waste Electronic Products in H city}

According to the distribution of $\mathrm{H}$ city electronics market, there are three of the most ideal product recycling points

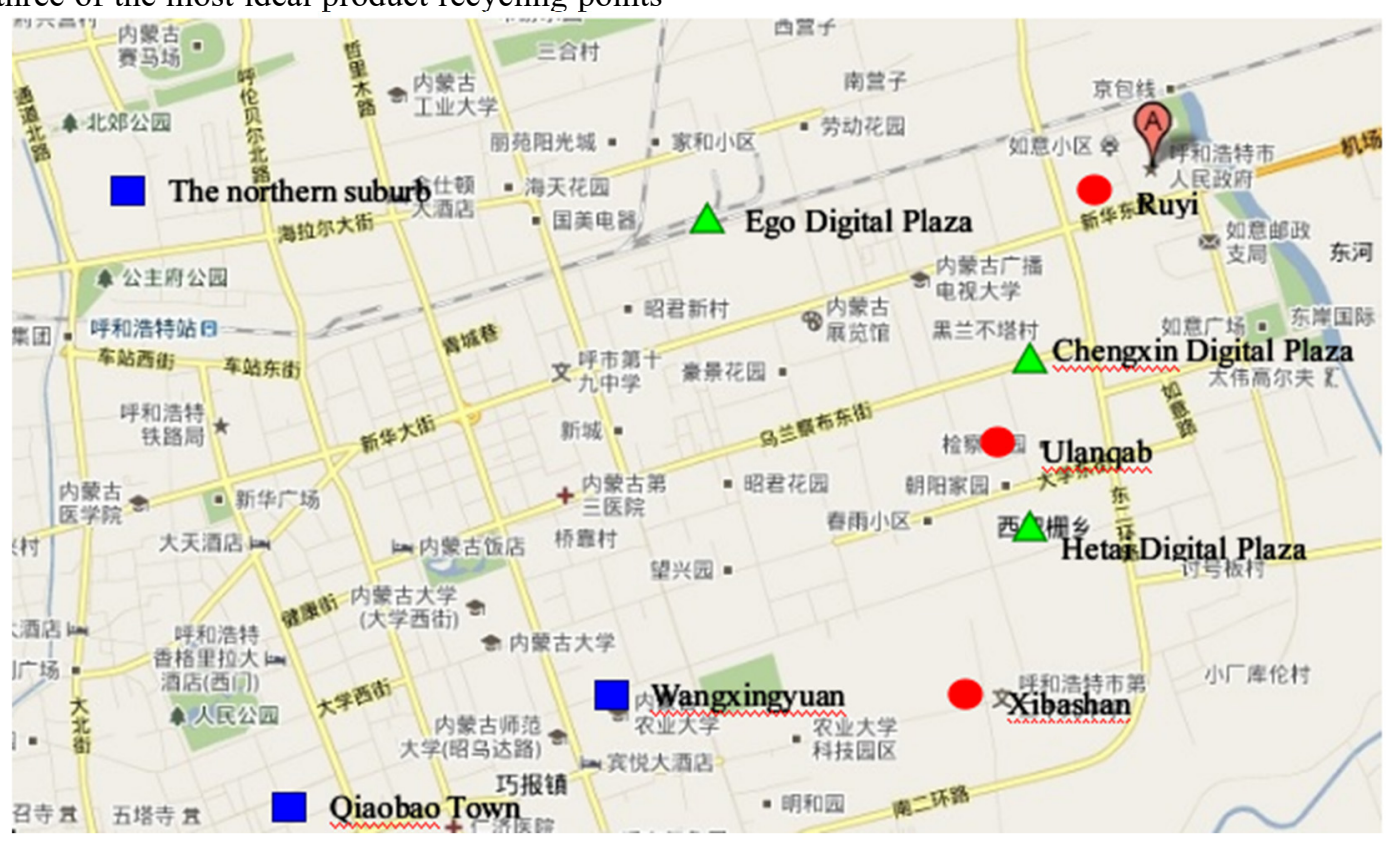

Fig. 2 Electronic and electrical appliances market distribution in H city

This paper selects two typical products, namely mobile phone chip and computer motherboard, as product $\mathrm{A}$ and product $\mathrm{B}$ for modeling analysis. Xibashan, Ulanqab and Ruyi are set as Recycling Point 1, Recycling Point 2, Recycling Point 3; the northern suburb, Qiaobao Town and Wangxingyuan are set as (located in Xibashan, Ulanqab, Ruyi), three processing plants (located in northern suburb, Qiaobao Town, Wangxingyuan) and three sales points (located in Chengxin Digital Plaza, Ego Digital Plaza and Hetai Digital Plaza). The distribution of recycling, processing and sales points of waste electronic products is shown in Figure 2.

Table 1 Sales prices of products A and B in each sales point

\begin{tabular}{|c|c|c|}
\hline & Product A & Product B \\
\hline Sales Point 1 & 97 & 83 \\
\hline Sales Point 2 & 80 & 79 \\
\hline Sales Point 3 & 108 & 83 \\
\hline
\end{tabular}

Table 2 Recycling/processing costs of products A and B

\begin{tabular}{|c|c|c|}
\hline & Product A & Product B \\
\hline Recycling Point 1 & 6 & 6 \\
\hline Recycling Point 2 & 4 & 7 \\
\hline Recycling Point 3 & 4 & 2 \\
\hline Processing Plant 1 & 3 & 2 \\
\hline Processing Plant 2 & 2 & 2 \\
\hline Processing Plant 3 & 2 & 8 \\
\hline
\end{tabular}

Table 3 Fixed costs for each processing plant

\begin{tabular}{|c|c|c|c|}
\hline & Processing plant 1 & Processing plant 2 & Processing plant 3 \\
\hline $\begin{array}{c}\text { Fixed costs of the } \\
\text { processing plant }\end{array}$ & 19 & 17 & 22 \\
\hline
\end{tabular}


Table 4 Fixed costs for each recycling point

\begin{tabular}{|c|c|c|c|}
\hline & Recycling point 1 & Recycling point 2 & Recycling point 3 \\
\hline $\begin{array}{c}\text { Fixed costs of the } \\
\text { recycling point }\end{array}$ & 12 & 21 & 15 \\
\hline
\end{tabular}

Table 5 Freight charges from the processing plant to the point of recycling and sales

\begin{tabular}{|c|c|c|c|c|c|c|}
\hline & $\begin{array}{c}\text { Recycling } \\
\text { point 1 }\end{array}$ & $\begin{array}{c}\text { Recycling } \\
\text { point 2 }\end{array}$ & $\begin{array}{c}\text { Recycling } \\
\text { point 3 }\end{array}$ & Sales point 1 & Sales point 2 & Sales point 3 \\
\hline $\begin{array}{c}\text { Processing } \\
\text { plant 1 }\end{array}$ & 6 & 7 & 3 & 8 & 10 & 12 \\
\hline $\begin{array}{c}\text { Processing } \\
\text { plant 2 }\end{array}$ & 3 & 4 & 5 & 5 & 7 & 8 \\
\hline $\begin{array}{c}\text { Processing } \\
\text { plant 3 }\end{array}$ & 5 & 6 & 8 & 6 & 9 & 14 \\
\hline
\end{tabular}

Table 6 Distribution function of recycling quantity/demand of product A and B at various points

\begin{tabular}{|c|c|c|}
\hline & Product A & Product B \\
\hline Recycling point 1 & $\mathrm{U}(145,235)$ & $\mathrm{U}(122,182)$ \\
\hline Recycling point 2 & $\mathrm{U}(123,233)$ & $\mathrm{U}(145,225)$ \\
\hline Recycling point 3 & $\mathrm{U}(103,203)$ & $\mathrm{U}(93,203)$ \\
\hline Sales point 1 & $\mathrm{U}(75,125)$ & $\mathrm{U}(33,133)$ \\
\hline Sales point 2 & $\mathrm{U}(66,106)$ & $\mathrm{U}(61,121)$ \\
\hline Sales point 3 & $\mathrm{U}(44,84)$ & $\mathrm{U}(49,119)$ \\
\hline
\end{tabular}

Table 7 Illegal cost and excess disposal profit of product A and B

\begin{tabular}{|c|c|c|}
\hline & Product A & Product B \\
\hline The cost of default & 1 & 3 \\
\hline Excess disposal profit & 3 & 1 \\
\hline
\end{tabular}

Table 8 Processing capacity of each processing plant

\begin{tabular}{|c|c|c|c|}
\hline & Processing plant 1 & Processing plant 2 & Processing plant 3 \\
\hline $\begin{array}{c}\text { Maximum processing } \\
\text { capacity }\end{array}$ & 194 & 237 & 259 \\
\hline $\begin{array}{c}\text { Minimum processing } \\
\text { capacity }\end{array}$ & 20 & 32 & 43 \\
\hline
\end{tabular}

The data in Tables 1-8 are substituted into the reverse logistics model of electronic products and solved by LINDO6.1. The calculated results are as follows:

The optimal value of objective function $\pi=72723-12-21-15=72675$,

$$
\begin{aligned}
& f_{1}=0, f_{2}=1, f_{3}=1, x_{131} 190, x_{221}=178, x_{321}=153, x_{132}=151, x_{222}=58, x_{232}=127, x_{322}=148, x_{231}^{\prime}=331, x_{331}^{\prime}=190, x_{212}^{\prime}=206, \\
& x_{312}^{\prime}=278, M_{11}=100, M_{21}=86, M_{31}=-457, M_{12}=-401, M_{22}=91, M_{32}=84, N_{11}=-100, N_{21}=-86, N_{31}=475, N_{12}=401, \\
& N_{22}=-91, N_{32}=-84
\end{aligned}
$$

\subsection{Reverse Logistics Implementation Plan for Waste Electronic Products in H city}

According to the results of the model solution, the product recycling points of Xibashan, Ulanqab and Ruyi were all selected, the processing plants Qiaobao Town and Wangxingyuan were selected, and the sales points of Chengxin Digital Plaza and Hetai Digital Plaza were selected. The specific recycling implementation scheme is shown in Figure 3.

In the implementation plan of recycling waste electronic products, Xibashan transported 1190 units of product A and 2151 units of product B to Wangxingyuan. Ulanqab transported 1178 units of product $A$ and 258 units of product $B$ to Qiaobao Town. Ulanqab transported 2127 units of product B to Wangxingyuan. Ruyi transported 1153 units of product A and 2148 units of product B to Qiaobao Town. Qiaobao Town transported 1331 units of new product A to Hetai Digital Plaza and 2206 units of new product B to Chengxin Digital Plaza. Wangxingyuan transported 1190 units of new product A to Hetai Digital Square and 2278 units of new product B to Chengxin Digital Plaza. 


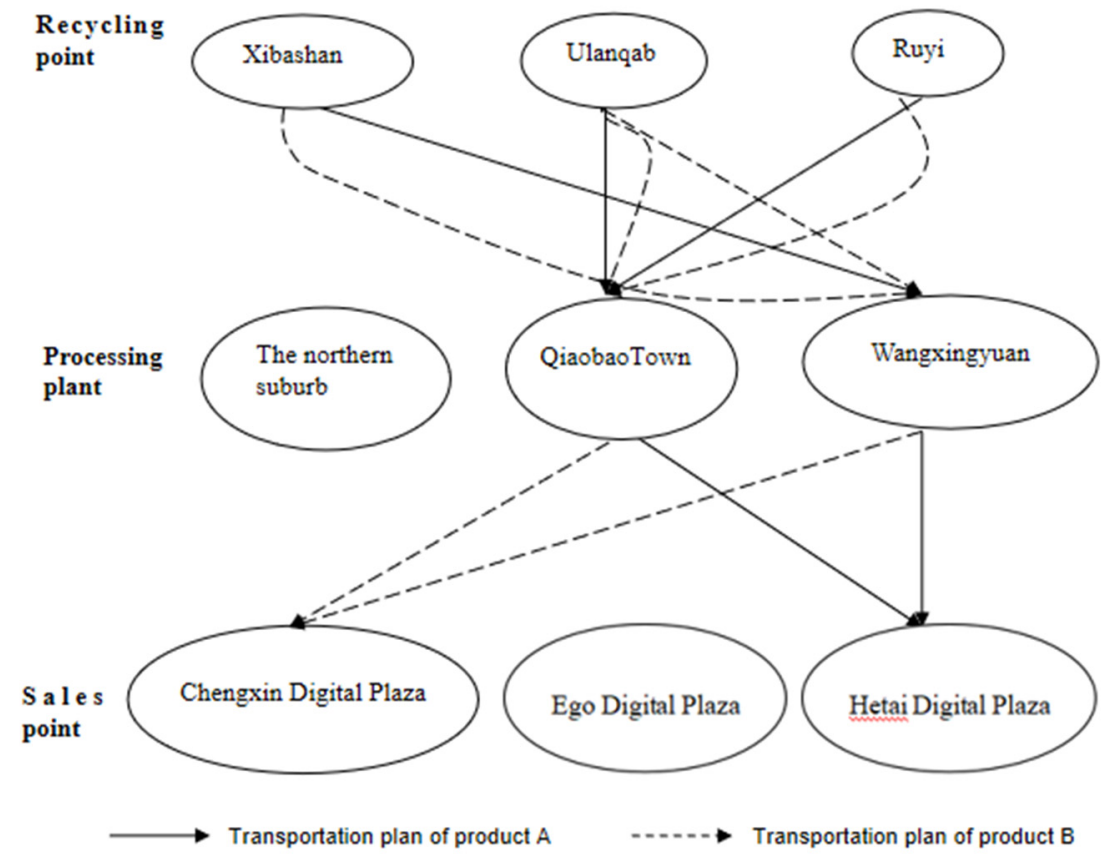

Fig. 3 Schematic diagram of reverse logistics implementation plan of waste electronic products in $\mathrm{H}$ city

\section{Conclusion}

China is a big producer and consumer of electronic products. The increasingly serious pollution of waste electronic products has become one of the focuses of people's livelihood. In view of the potential environmental pollution and recycling of renewable resources of waste electronic products, China should actively promote the recycling and processing industry of waste electronic products, strengthen the construction of reverse logistics network, establish and improve the recycling and utilization system of waste electronic products, and promote the healthy and sustainable development of environmental protection and economic society.

\section{Author}

Zheng Ning, associate professor, master candidate, research interest: supply chain management.

\section{References}

1. Website of the National Development and Reform Commission, PRC [EB/OL]. https://www.ndrc.gov.cn

2. Moritz, Fleischmanna, Hans Ronald Krikker, Rommert Dekker, Simme Douwep. Flapper. A Characterisation of logistics networks for product recovery [J]. The International Journal of Management Science, 2000, (28) :653 666.

3. Theresa J Barker. Reverse Logistics: A Multi-Criteria Decision Model with Uncertainty[D]. University of Washington. 2010.

4. Xu Yunliang. Research on Reverse Logistics Network Planning of Waste Electronic Products [D]. Tianjin Polytechnic University, 2017

5. Xu Jian, Zhang Yunli, Jin Yuran. Research on Recycling Network of Waste Electronic Products [J]. Logistics Science and Technology, 2015(03):56-59.

6. He Yi, Ji Guojun. Analysis of reverse logistics in electronic product industry [J]. Special Zone Economy, 2016(01): 29-33 